\title{
A Viagem e a Memória do Idoso: um estudo na região da Serra Gaucha
}

\section{Traveling and the Memory of Senior Citizens: a study in the region of Serra Gaucha}

Susana de Araújo Gastal ${ }^{1}$

Ana Maria de Paris Possamai ${ }^{2}$

Airton da Silva Negrine ${ }^{3}$

\section{Resumo}

O artigo descreve os resultados da pesquisa com idosos, instigados a relatar experiências de viagens e lazer na sua juventude, utilizando-se como metodologia a história oral. A investigação foi realizada na Serra Gaúcha, extremo sul do Brasil, hoje uma das mais pujantes regiões de turismo do país que, na primeira metade do século $\mathrm{XX}$ - período rememorado pelos entrevistados - ainda apresentava precariedades na sua infra-estrutura de transportes. A partir de reflexões teóricas sobre a questão da memória analisam-se, especificamente, os relatos dos idosos em termos de viagens por eles realizadas na sua juventude. Os entrevistados, na sua totalidade ítalo-descendente de origem rural, diferenciam nos seus relatos as viagens ocorridas na infância, daquelas realizadas na juventude e na idade adulta. Os participantes do estudo avaliaram o momento presente como o mais qualificado e diferenciado dos anteriores, em termos de desfrute do lazer e das viagens que realizam. As respostas também encaminham uma série de dados que contribuem para a construção da história das viagens e do turismo no Brasil.

Palavras-Chave: turismo; memória; história das viagens; Serra Gaucha/RS/Brasil

\begin{abstract}
The article describes what senior citizens reported as experiences of travel and leisure in their youth. The methodology used was oral history. The research was conducted in southern Brazil, currently one of the most vigorous areas of tourism in the country. But, in the first half of the twentieth century - the period remembered by the people interviewed -the region had a precarious transport structure. The theoretical reflections on memory analyze the elderly's histories in terms of the trips they made in their youth. The interviewees, Italian descendants with rural backgrounds, report that traveling occurred in their childhood, youth and adulthood. The participants evaluated the present moment as the most qualified and distinguished than the previous in terms of enjoyment of leisure and travel. The data also contributes to the construction of the history of traveling and tourism in Brazil
\end{abstract}

Keywords: tourism; memory; tourism history; Serra Gaucha/RS/Brasil

\footnotetext{
${ }^{1}$ Doutora em Comunicação Social pela Pontifícia Universidade Católica do Rio Grande do Sul (PUC-RS); Pesquisadora, Orientadora e Professora do Programa de Pós-Graduação - Mestrado de Turismo da Universidade de Caxias do Sul (UCS). E-mail: susanagastal@gmail.com

${ }^{2}$ Mestre em Turismo pela Universidade de Caxias do Sul. E-mail: am.possamai@uol.com.br

${ }^{3}$ Doutor em Filosofia e Ciências da Educação pela Universidade de Barcelona - Espanha (UB); Pesquisador, Orientador e Professor do Programa de Pós-Graduação - Mestrado de Turismo da Universidade de Caxias do Sul. E-mail: negrine@portoweb.com.br
} 


\section{Preliminares ao Estudo}

A palavra lembrar tem origem no francês se souvenir/sous-venir, significando o vir à tona, o vir de baixo. O afloramento do passado (BOSI, 1994, p. 46) viria combinado com o processo de percepção atual. Memória, por sua vez, derivaria de Mnemosine, a mãe das musas, na mitologia grega, vista como protetora das Artes e da História (KURY, 2009). Kessel (s/d) afirma que, entre os gregos, os registros escritos seriam mal vistos, pois, ao transferir para fora do corpo um saber, o sujeito enfraqueceria a sua memória. Dessa forma, os helenos desenvolveram técnicas para preservar a lembrança sem utilizar suportes materiais de memória. Os poetas, por exemplo, tinham o papel social de transmitir, por meio do canto e da poesia, as histórias e os conhecimentos que não deveriam ser esquecidos, mantendo-os vivos na memória coletiva. Daí, também, o papel social e importância dos idosos nessa e em outras sociedades cuja cultura for baseada na oralidade, por serem responsáveis por manter viva as tradições, as histórias e os saberes do grupo.

Por essas razões, entre outras, a memória desempenha importante papel social, assim como pessoal, ao permitir a manutenção e reprodução de conhecimentos e experiências. $\mathrm{Na}$ contemporaneidade, mesmo que a memória biológica conviva com diferentes suportes exteriores de memória - do livro ao cdrom - ela ainda desempenha papel importante na transmissão de vivência e de conhecimento entre as gerações. Nas sociedades primevas e nômades, uma das funções dos anciãos era a de conduzir o grupo nos seus deslocamentos, motivados pela busca de alimento e/ou de melhores condições climáticas, ou mesmo por razões religiosas, pois a boa-vontade das divindades também seria fundamental à sua sobrevivência em um meio ambiente quase sempre hostil.

A vida sedentária, posterior, não diminuiu, necessariamente, a importância social dos idosos, nem impediu o deslocamento das pessoas, mas a viagem passou a ter outros objetivos e finalidades, como os cuidados com a saúde e a participação em feiras e festas religiosas. Para Leed (1991), a palavra viagem manterá a carga simbólica e mitológica da ação que a originou, levando-a a transformar-se em metáfora utilizada para explicar transformações e transições vitais como a morte (viagem sem retorno) ou a vida (jornada sobre a terra). Com a Modernidade, em especial ao longo do século XX, a palavra turismo abarcará as viagens motivadas pelo lazer e, ao deslocamento, serão agregados outros fatores constituintes do fenômeno, como o alojamento, a alimentação e o atrativo, entre outros. 
Outro fator a destacar é que as análises críticas do fenômeno turístico em termos de motivações para as viagens dão conta que estas estão associadas a uma visão de mundo e a necessidades européias para os deslocamentos (BARBOSA, 2002; REJOWSKI, 2002; BOYER, 2003), o que não tem impedido que as tipologias e periodizações daí decorrentes sejam, por vezes, adotadas como uma história oficial e universal do Turismo, tendo em vista a hegemonia política dos países onde estes estudos se originam. Partindo-se do pressuposto que o viajar é um fenômeno social e, como tal, pertinente aos modos de viver de diferentes sociedades, é possível questionar que necessidades, urgências e prazeres teriam motivado os deslocamentos em locais fora dos eixos hegemônicos, como, no presente caso, os espaços coloniais e de capitalismo periférico como, por exemplo, o sul do Brasil na primeira metade do século XX. Ou seja, como o imaginário sobre o viajar se constitui em sociedades periféricas. Temos poucos registros, e essa é uma história que está por ser escrita.

Com a intenção de responder a este questionamento, entre outros, realizou-se um estudo empírico com idosos residentes na Região da Serra Gaúcha, no extremo sul do Brasil, com o objetivo de suas resgatar experiências pregressas de viagens e de práticas de lazer, cujas respostas vieram sob o mote "quando éramos jovens". Como os idosos entrevistados tinham em média 75 anos, a expressão pode remeter ao tempo fabular do era uma vez das narrativas infantis, mas também a um tempo anterior, não preciso, envolvendo infância, juventude e ingresso na vida adulta. O estudo foi realizado em 2008, no decorrer da disciplina Turismo e Cultura, do Curso de Graduação em Turismo da Universidade de Caxias do Sul, campus de Bento Gonçalves/RS, com atuação na região pesquisada. O objetivo didático do exercício de pesquisa, inicialmente, era o de associar questões práticas aos estudos teóricos sobre memória e identidade, parte do conteúdo da disciplina, assim como ampliar as aproximações entre turismo e memória, para além dos estudos sobre a preservação arquitetônica e sobre o acervamento de objetos em museus. Para fins da pesquisa e das reflexões aqui apresentadas, priorizou-se o vocábulo viagem - que, nestes termos, tem como significado o caminho percorrido para chegar a outro lugar, que não aquele onde o indivíduo reside -, mais familiar ao universo vocabular dos entrevistados. Entretanto, a palavra turismo também foi por eles bastante utilizada. 
Como metodologia, utilizou-se a história oral. O instrumento de coleta de informação foi a entrevista semiestruturada, a partir de um roteiro aberto, realizadas pelos alunos do curso ${ }^{4}$. Como estratégia de coleta de informações, cada aluno teve a incumbência de entrevistar um idoso pessoa com mais de 60 anos, preferencialmente, de suas relações pessoais. Adotou-se esse método de coleta de informações baseado em Bosi (1994), que afirma que o grau de confiança entrevistador/entrevistado torna a abordagem natural e facilita o desenrolar da entrevista. Também se considerou que a história oral pode representar uma importante contribuição ao inventário turístico com vistas ao planejamento local, e que a maior familiaridade dos educandos com a mesma, poderá auxiliá-los no futuro desempenho profissional.

As respostas foram gravadas e transcritas, mas não houve a validação pelos entrevistados, uma vez que o propósito inicial da pesquisa era, apenas, o de oportunizar aos alunos a experiência de campo. A qualidade do material, entretanto, instigou os autores a aprofundar a análise dos dados e a socializar os resultados. No total foram selecionadas 19 entrevistas. Os idosos entrevistados tinham, quando entrevistados, entre 61 a 89 anos e residiam nas cidades de Bento Gonçalves, Carlos Barbosa, Caxias do Sul, Farroupilha, Garibaldi, Nova Prata e Veranópolis, todas situadas na região turística da Serra Gaúcha. A análise das informações permitiu aquilatar as práticas de lazer e as viagens que os entrevistados realizaram na sua juventude. Por ocasião das entrevistas, indagou-se se relembravam das viagens da sua juventude, que meios de transporte eram então utilizados e as motivações para esses deslocamentos.

Para introduzir a descrição e análise dos dados colhidos, realiza-se um resgate teórico sobre como a questão da memória vem sendo abordada pelos especialistas. A seguir, apresentam-se os dados coletados, para contextualizá-los em termos do como e do por que viajar na região, na primeira metade do século XX - espaço e período abarcados pelas lembranças dos entrevistados. No período rememorado, a região apresentava equipamentos e vias de transporte ainda precários, pois recebeu a presença de migrantes europeus somente a partir da década de 1870. Antes, a região era esparsamente habitada por ameríndios, que foram expulsos ou dizimados no processo de colonização. Os danos ocasionados na luta pela posse do

\footnotetext{
${ }^{4}$ Participaram das entrevistas, os seguintes alunos: Andreia Cichelero; Cristiane Kehl; Elza Brandalise; Fatima J. Grando; Lisete Zechin; Lizara Berté; Naiara E Martini; Josiane M. Pezzini; Julielen L. Peixoto; Keli Waskiewicz; Letícia Rombaldi; Rafael Tierling; Roseli G. Dal Pizzol; Samara da Silva; Silmara de Souza; Sinval Gatto Junior; Tatiana Canal; Thiago Simonetto; Vanessa C.B. Oliveira; Vanessa Palharini.
} 
território não invalidam considerar as péssimas condições iniciais a que foram relegados os primeiros imigrantes europeus na região, inclusive para sua sobrevivência física, em terrenos íngremes e cobertos por matas nativas. No caso específico da região em análise, o nordeste do Rio Grande do Sul, os migrantes eram em sua maioria agricultores, vindos do norte da Itália. Mas entre eles haveria também artesãos, ferreiros e marceneiros, uma mão-de-obra desnecessária no novo processo industrial europeu daquele momento e, portanto, expulsa do continente junto com os agricultores.

Se no primeiro momento na nova terra os migrantes priorizaram, por obvio, a agricultura de subsistência, logo o excedente da produção pôde ser comercializado em armazéns instalados em pontos estratégicos em termos de fluxos, mas o deslocamento até eles era precário, feito por piquetes abertos no meio da mata e percorridos a pé ou com tração animal. Em 1881 foi aberta a primeira estrada onde podiam transitar carroças. O trem só chegou à região em 1910. Para dimensionar as dificuldades de transporte, mesmo na década de 1950 só havia uma "linha" de ônibus que ligava as cidades de Bento Gonçalves e Caxias do Sul, as maiores da região. Como apresentado adiante, este cenário de precariedades nos deslocamentos será muito enfatizado nas entrevistas. Em que pese às dificuldades, em menos de cem anos a região se colocará como um dos principais pólos industriais e vitivinícola do Brasil, hoje com excelência na produção de vinhos, espumantes, e em enoturismo. As tradições italianas ainda são cultuadas na zona rural, tornando-as apropriadas ao turismo de regate de raízes e de tradições.

\section{A Memória e Contexto Social}

Falar nas relações entre turismo e memória implica alguns vieses. Começando pela aproximação mais óbvia, os produtos memorialísticos são muito relevantes no turismo. Prédios antigos, tradições, canções, hábitos alimentares, entre muitos outros, servem de atrativos aos viajantes e costumam ser utilizados por aqueles que planejam e fazem a gestão turística. Entretanto, é possível afirmar que haveria certa obviedade nos elementos de memória utilizados, depois que o passado virou importante item de mercado, levando a repetições e mesmices que estariam na contramão das demandas dos novos segmentos de consumidores de viagens, muito mais exigentes em termos de qualidade e originalidade.

\footnotetext{
${ }^{5}$ A expressão "linha" refere ao percurso regular, feito por transporte coletivo.
} 
Retomar o passado narrado pela comunidade local pode contribui para incorporação de práticas do antigamente, em novas experiências para os turistas contemporâneos. Outro viés importante a estudar está relacionado com as lembranças dos idosos, pertinentes às viagens que realizaram, para saber de que maneira elas contribuíram para sua qualidade de vida.

Em ambos os casos, faz-se necessário encaminhar, em primeiro lugar, o entendimento a respeito da memória. Cardoso (1997), por exemplo, é de opinião que a memória surge como um processo de retenção de informações no qual as experiências são arquivadas e recuperadas quando demandadas. Para Izquierdo (1999), um dos maiores especialistas no tema, a memória supõe aquisição, formação, conservação e evocação das informações que o ser humano recolhe nas suas experiências de vida. O pesquisador ensina que, para ser lembrada, a informação deve, antes, ser armazenada e que a posterior evocação significaria recordação, lembrança, mas, principalmente, recuperação.

A memória está relacionada à função cerebral superior, sendo uma faculdade cognitiva de extrema importância para o aprendizado, tanto no armazenamento de informações, como no aproveitamento de experiências. A memória nas considerações de Cardoso (1997) funciona como suporte a aquisição do conhecimento e permite ao sujeito considerar o passado, situarse no presente e planejar o futuro. Na mesma direção, Izquierdo (1999) entende que há três tipos de memórias, funcionando como sistemas independentes e interligados: a memóriatrabalho, que mantém a informação viva durante os segundos ou poucos minutos em que está sendo percebida ou processada, e que não deixa traços posteriores; a memória de longa duração, que permanece por horas, dias ou anos, e que não se forma instantaneamente, mas num processo de várias horas, numa seqüência de passos moleculares, suscetível a numerosas influências; e a memória de curta duração que se traduz pelo processo ou conjunto de processos que mantém a memória funcionando durante o tempo em que a de longa duração está adquirindo sua forma definitiva.

Por razões biológicas e psíquicas, não é viável ao ser humano armazenar tudo, o mesmo valendo para a recuperação. Nos dois casos, há uma seletividade, segundo Izquierdo (1999). Esse autor sustenta que o indivíduo é aquilo que ele recorda, ou seja, que a própria identidade pessoal e a social estariam associadas ao que é lembrado, ou esquecido, sobre o si e sobre o coletivo. A memória, nestes termos, é fator marcante da individualidade e define as 
identidades dos seres humanos. A memória coletiva determinaria identidades de comunidades, nações ou regiões.

Izquierdo (1999) diz ainda que, considerando o conteúdo que revela, haveria memórias declarativas ou explícitas - aquelas que se referem a tudo que o indivíduo pode relatar e reconhecer como memórias, como fatos, rostos, textos; e memórias de procedimentos ou implícitas, envolvendo os hábitos que a pessoa adquire e evoca mais ou menos automaticamente, como ao andar, nadar, ou ao consultar a lista telefônica sabendo de suas convenções. Bosi (1994) segue em caminho semelhante e fala em memória-hábito e em imagem-lembrança. A primeira envolveria o adestramento cultural, como os hábitos nos quais o indivíduo está inserido, como a forma de se portar à mesa, a linguagem, a vestimenta e, também as habilidades adquiridas, como dirigir, escrever, costurar, dançar, em resumo, o que é utilizado diariamente. A memória imagem-lembrança resgataria momentos únicos, com data certa, refere-se a uma situação específica e individual que, ao ser evocado, traz consigo também as emoções do momento vivido. Da análise dos dois especialistas, deduz-se que aquilo que Bosi denomina como memória-hábito, para Izquierdo, seria a memória de procedimentos ou implícita, e a memória imagem-lembrança, de Bosi, equivaleria a memória declarativa ou explícita de Izquierdo.

Bosi (1994) acrescenta que a memória, além de reter as informações e manifestações do presente, também as relaciona com o passado. Dessa forma, a memória criaria representações, as quais transformam a simples percepção do presente em experiências únicas e individuais. De acordo com Bosi, a memória funciona como um espelho da realidade, de tudo o que cerca o indivíduo. Atos e objetos são comparados como o banco de dados da memória. Recorrendo a Bergson, Bosi diferencia lembranças de percepções e idéias, ao dizer que estas nascem no presente corporal contínuo e a lembrança, por outros meios.

Acompanhando a valorização da memória, a história oral ganhou terreno no campo das ciências humanas, como metodologia de pesquisa. Antropólogos, sociólogos e historiadores têm buscado nas lembranças dos mais velhos recursos para reconstruir trajetórias sociais. Bosi (1994) questiona se o movimento de recuperação da memória seria uma moda acadêmica ou teria origem mais profunda, carregando consigo necessidade de enraizamento. A autora acredita que o vínculo com o passado se traduz na formação da identidade dos indivíduos e valoriza o sentimento de pertença. Sendo assim, a busca pela reconstrução da história por meio do resgate 
das memórias individuais, ganha status de reencontro da sociedade com seu passado, das novas com as antigas gerações, promovendo um processo saudável de troca de experiências.

Bosi (1994) ainda esclarece que a memória coletiva resulta de um processo de coleta de relatos, o mesmo fato relatado por diferentes integrantes do grupo, como se fosse passado a limpo. Das contribuições de todos se constrói a memória coletiva, sendo que, esse processo pode ocorrer espontaneamente, em conversas informais, nas quais cada um expõe suas lembranças de determinado fato, em geral as lembranças convergem. Outras vezes, principalmente quando se referem a questões familiares, podem existir divergências, afirma a autora, com base em sua própria experiência.

As lembranças fazem parte do processo de reconstrução do passado vivido e presenciado, de certo modo, ao serem relembrados, os fatos produzem novas emoções, são revividos. As pessoas idosas não possuem tantas obrigações de trabalho, com horários a cumprir e uma agenda cheia de compromissos. Por tudo isso, sua memória fica liberada para refletir e recuperar eventos passados com maior riqueza de detalhes. Bosi afirma que essa característica dá ao idoso a função social de lembrar, de ser a memória da família e da sociedade.

Para Bosi (1994) os fatos e episódios resgatados correspondem à época que a pessoa possuía agilidade e uma longa perspectiva de vida pela frente e destacam a importância das lembranças para os idosos, como uma forma de se conectarem com sua própria identidade. A autora ainda chama atenção a pouca valorização do idoso pela sociedade, o que de certo modo invalida sua capacidade de transmissão de conhecimentos. Seus relatos, entretanto, se apresentam riquíssimos, e registram como as experiências e as dificuldades por eles enfrentadas contribuíram para construção da sociedade atual; fundamentalmente, estão eles dispostos, de forma solícita, a continuar contribuindo. Os idosos buscam apenas encontrar ouvidos para seus relatos, afirma a autora.

Bosi (1994) questiona e responde: Por que decaiu a arte de contar histórias? Talvez porque tenha decaído a arte de trocar experiências. A troca de experiências foi substituída pela tecnologia, prossegue a autora, o mundo antes orientado pelos ciclos naturais, hoje é orientado pelo poder da mídia. O idoso perdeu o papel de transmitir conhecimentos, de ensinar habilidades, de explicar processos. Atualmente são as escolas que têm o papel de ensinar um ofício. Os jogos e brincadeiras são eletrônicos, perdeu-se a técnica de confeccionar os 
próprios brinquedos, e principalmente, perdeu-se a prática da brincadeira em grupo. Se esta é, hoje, a perspectiva associada ao lazer, os relatos a seguir mostram outras práticas e outras formas de socialização, como formas de qualificar as vivências. E que, quase na sua totalidade, o lazer supunha algum tipo de deslocamento, ou melhor, viagem.

\section{A viagem recordada}

A memória, como relatado, tem funções que vão além do individual, constituindo um elo entre o passado e o presente, entre o indivíduo e sua coletividade. A pesquisa realizada com os idosos, no Rio Grande do Sul, possibilitou reflexões sobre questões relativas aos deslocamentos e aos lazeres na sua juventude, ou seja, entre o presente e o passado. Também oportunizou aos alunos que realizaram as entrevistas, conhecer melhor um grupo social pujante na atividade turística e a história das viagens na região da Serra Gaucha.

A maioria dos entrevistados "viveu da roça”, como expressou MIPL (82) ${ }^{6}$, explicando referirse às origens rurais envolvendo "plantação de milho, arroz, feijão, mandioca. Praticamente nada era comprado de comida. Apenas "a carne bovina era comprada às vezes, quando era possível". A mesma depoente disse que as viagens ocorriam "uma ou duas vezes por ano, apenas para visitar parentes na cidade próxima [...] além de fazer as compras de Natal nas proximidades". Relato semelhante foi feito por MMD, que preferiu não declarar sua idade. Disse a depoente: “Morávamos no interior, então nossas maiores viagens eram quando íamos à cidade, montados em cavalos ou carroças puxadas por bois. Nas famílias mais ricas, essas viagens eram feitas em charretes, puxadas por cavalos."

Embora os idosos entrevistados tivessem idades entre 61 e 89 anos, e suas memórias reportem às décadas de 1930, 1940 e 1950, apenas três, por residirem no núcleo urbano das localidades, não citaram o cavalo como o meio de transporte na sua juventude. Mesmo os participantes mais jovens, na faixa etária entre 61 e 63 anos, fizeram referências ao cavalo como sendo o principal meio de transporte na época, tanto para ações das rotinas de trabalho, como para o lazer. Como colocado por IBM (67), "como a igreja era distante, no início era a cavalo que a gente ia à missa, que era no lugar mais perto. O meio de transporte era cavalo ou a pé,

\footnotetext{
${ }^{6}$ Com o objetivo de resguardar a identidade dos entrevistados, as referências a eles são feitas utilizando-se as letras iniciais do pré-nome e nome, com a respectiva idade ao lado.
} 
mesmo". Outra depoente, AMC (89), complementa: "Ninguém se importava de caminhar, estávamos acostumados”. Ainda sobre o caminhar, JC (82) complementa:

Não tenho muitas lembranças de viagem. Lembro que quando eu era criança caminhávamos bastante para ir até a cidade, principalmente na missa. Nós caminhávamos em grupos, a maioria famílias, e as famílias eram muito numerosas. Nós, mais jovens, não íamos todos os domingos na missa, mas os mais velhos (pai e mãe) iam todos os domingos, mas iam a cavalo.

Explicando a dificuldade, VB (61) opinou: “Ônibus só de David Canabarro até Passo Fundo; as estradas eram de chão batido”. Isso para destacar que não havia pavimentação das estradas que ligavam uma cidade a outra. A participante NGG (75) informou que teria viajado de trem entre Garibaldi e Carlos Barbosa e, em 1953, teria ido de trem até Caxias do Sul, na viagem de núpcias. De Caxias do Sul à Ana Rech - localidade que hoje é um dos bairros de Caxias -, utilizou o ônibus, para passar a lua-de-mel num hotel da localidade. Também foi citado, pelos entrevistados que residiam na zona rural, o caminhão como meio de transporte, o que também era muito comum na época. Segundo alguns depoentes:

As viagens de cerca de 50 anos atrás eram feitas a cavalo, posteriormente a "linha" [era percorrida por] uma espécie de ônibus com bagageiro na parte superior e coberto por lona. Estas viagens duravam o dia todo para fazer alguns quilômetros [...]. A estrada possuía dificuldade de ter barrancos, pedras soltas, barro nos dias de chuva e poeira nos dias limpos. (AS, 67)

O ônibus na época não era um transporte coletivo acessível a todos, como fica claro no depoimento de CMS (68):

Algumas pessoas iam de ônibus, mas as passagens eram caras e eu não tinha condições de pagar, sendo assim, tratava de arrumar carona sobre caminhões de toras que daqui iam para Bento Gonçalves. Estas viagens de 100 quilômetros chegavam a durar de cinco a dez horas, pois a estrada era precária. [...] Quando fiquei mais velha, não lembro quantos anos eu tinha, começaram a aparecer os primeiros carros. Parecia um ônibus com cara de Jeep, mas não era nenhum dos dois, mas novamente só os ricos tinham esse tipo de veículo. Para andar de carro só ganhando carona ou sendo amigo deles. (CMS, 68).

Um dos entrevistados, reportando a década de 1950, destacou as peculiaridades da paisagem, que segundo ele, era: 
$\mathrm{Na}$ grande maioria mata, com uma pequena estrada de chão batido (piquete) cortando a mata. Apesar da mata havia dificuldade no caminho, animais peçonhentos como cobras e aranhas, raposas, ouriços, cachorros do mato, porco do mato e outros. [...] A vegetação na sua maioria era pinheiro.” (AS, 67).

Afirmou, ainda, o depoente, que a aventura de viajar não terminava aí:

Quando a viagem era longa, a noite era passada no mato com lonas armadas na forma de barracas, onde dormiam no chão batido. Com o chegar da noite eles procuravam lenha para fazer uma fogueira, também ficava uma pessoa acordada de vigia enquanto as outras descansavam [...] Os cavalos eram acorrentados nas plantas durante a noite para não fugirem se escutassem o barulho dos leões baios ${ }^{7}$. [...] A alimentação era levada para viagem, pois não existia restaurantes pelas pequenas estradas. Eles levavam mantimentos como pão, salame, queijo e água que deveriam durar a viagem toda". (AS, 67).

As razões das viagens, na memória dos entrevistados, parecem dividir-se claramente pelas faixas etárias. Quando se referem ao quando eram crianças, os pais é que viajavam. Segundo IBM (67), isso se dava "pois era longe, demorava, pois não tinha acesso a ônibus, como agora". Apenas os filhos mais velhos, às vezes, acompanhavam os pais, cuja finalidade era a de visitar parentes, em especial, avós, quando estes residiam em outra localidade. As viagens eram feitas nos finais de semana e os viajantes não costumavam ficar mais de três dias longe de casa, devido às tarefas que tinham em suas propriedades. Muitas vezes essas viagens de visitas aos familiares aconteciam apenas uma vez ao ano, justamente devido à falta de transporte. Outros depoentes acrescentam mais detalhes sobre as viagens, explicando que, naquele momento, entre as décadas de 1930 e 1950, elas estariam também relacionadas a compras, visita a doentes, ou a se fazer presente em funerais, aniversários, casamentos e até mesmo por razões profissionais:

As viagens naquela época não eram para turismo e sim para visitar parentes, mudar de localidade, ir aos filós ${ }^{8}$, velórios e enterros. (AS, 67).

[...] a gente ia para as cidades mais próximas, só fazer compras e essas coisas. [...] naquela época os pais iam visitar os parentes. Mas [só] de vez em quando. A cada meio século... (risadas). (IBM 67).

\footnotetext{
${ }^{7}$ O leão baio é o mesmo que o também chamado vulgarmente de puma, suçuarana, onça-parda (Puma concolor). Ainda há alguns exemplares na região, e estão ameaçados de extinção (Prof. Rosana Lanser).

${ }^{8}$ Filós eram encontros comuns entre os italianos da zona rural. Varias famílias se reuniam, à noite, para conversar, jogar, ou realizar trabalhos manuais
} 
Não se faziam muitas viagens como hoje, somente os mais velhos como o meu pai que vendia o gado para o estado do Paraná e iam levar a cavalo, demorava dois ou três meses para fazer o percurso de ida e volta. $(\mathrm{VB}, 61)$.

Por cerca de cinco anos eu fui quinzenalmente ao lombo do cavalo, levando cerca de 300 cabeças de boi por vez a cidade de Vacaria, sendo que algumas a Passo Fundo. No lombo de cavalo se passa frio, fome e muito medo. (CMS, 68).

A vida adulta, e em especial o casamento, passam a demarcar um novo período e outras motivações para as viagens, iniciada com a denominada lua de mel: "Passei a fazer algumas pequenas viagens depois que casei, mas eram apenas para casa de parentes meus ou do meu falecido marido, já que antigamente os hotéis eram muito caros, somente os ricos é que se hospedavam”. (AMPR, 72).

As dificuldades dos deslocamentos continuam presentes na vida adulta, mesmo que agora o ônibus e o caminhão sejam incorporados para facilitar as viagens. As dificuldades não se limitavam as distâncias percorridas, mas incluíam as precariedades das poucas estradas existentes: "Aqui em Bento (Gonçalves) já tinha ônibus que passava quando eu casei. Que vinha de (Carlos) Barbosa, fazia Garibaldi e Bento, pela estrada Buarque de Macedo, que ia até a cidade. E tinha outro que voltava às quatro e meia e só, sim, de tarde. E de manhã, se não tinha, a gente ia de a pé ou fazia alguma coisa, né?” (IBM,67). Outro problema apresentado é que "a passagem era cara na época" (IK, 65).

O trem também começa a aparecer como veículo para as viagens, na memória do depoente, na década de 1940:

Se ia a cavalo até as estações de trem, aí se embarcava e se ia até o destino que queria. Às vezes, dependendo do lugar, tinha que trocar de trem nas estações. Se comprava só uma passagem e ao descer de um trem para outro, os cobradores só carimbavam a passagem. As viagens não duravam muito tempo. Geralmente saiamos de manhã e voltávamos à noite, dependendo do percurso, e se fôssemos visitar um parente ficávamos muito tempo na outra cidade. ( ) Eu viajava de trem ou se o caminho era mais curto era feito com os cavalos da família. Após meus 15 anos de idade, com a vinda dos ônibus para região, ocupávamos esse meio de transporte. (JG, 79).

Neste período, as viagens também passam a durar um pouco mais, "de sete a dez dias". (IK, 65) e a apresentar maior variedade de destinos: "Eu costumava passar as férias na casa de tios que moravam em Porto Alegre ou então no interior de Farroupilha, mesmo. Com meus irmãos era a mesma coisa” (MF, 63). JG (79) também relata uma diversidade de destinos: 
"Viajava bastante até Porto Alegre, Caxias do Sul, mas também conheci a cidade de Santa Maria, o estado de Santa Catarina, mais precisamente a cidade de Caçador. Também um país, o Uruguai”.

Para aqueles que frequentavam a escola na década de 1950, os passeios organizados pelos professores passam a se constituir em momentos especiais de viagem. Disse MF (63) que "tínhamos passeios com a escola, em que visitávamos outras cidades, voltando no mesmo dia ou algumas vezes passando o final de semana fora". Mesmo aos jovens, "os pais já permitiam que se fosse viajar nas férias para a casa de parentes. Ia-se sem a companhia dos pais".

Os habitantes do interior, como nas décadas anteriores, continuam indo ao núcleo urbano para assistir a missa e para trocar o excedente de produção por outros mantimentos que necessitassem, dentre eles o açúcar e o café e, também, para entregar os grãos de trigo e milho aos moinhos, para moer. Esses deslocamentos seriam mais frequentes, acontecendo uma ou duas vezes por mês. A maioria dos entrevistados destacou, também, que a família viajava para visitar parentes, confirmando a presença de laços familiares sólidos, no entanto, essas viagens ocorriam uma, no máximo duas vezes ao ano. Os que responderam viajar a trabalho também o faziam com mais frequência, sendo um dos entrevistados funcionário do DAER ${ }^{9}$, outro proprietário de uma serraria e os outros dois viajavam levando gado de uma cidade a outra. A Figura 1 expressa a distribuição das motivações, destacando-se a visita a parentes, seguida das compras. O culto religioso e a atividade profissional aparecem a seguir:

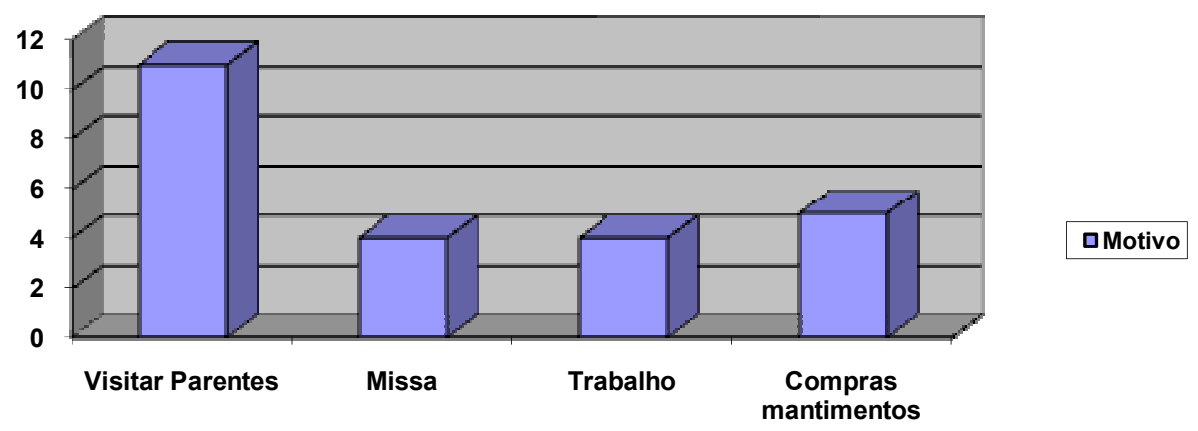

Figura 1 - Motivos do deslocamento

\footnotetext{
${ }^{9}$ Departamento Autônomo de Estradas de Rodagem do Rio Grande do Sul.
} 
A terceira etapa da vida dos idosos, em termos de viagens, está associada à fase em que os filhos já estão encaminhados na vida, como disse a participante MF (63). Momento em que o trabalho deixa de ser a prioridade. A mesma entrevistada explica, em relação aos seus pais: "Com apoio dos filhos meus pais começaram a frequentar grupos da melhor idade e participar de diversas atividades, entre elas as viagens. O humor e o ânimo deles melhoraram muito". (MF, 63). Será neste momento, que essas pessoas darão maior significado ao turismo, quando a viagem perde o caráter utilitário de atender compromissos com os mais velhos ou de participação em rituais como casamentos, aniversário e funerais.

A tradicional viagem ao litoral, comum em outras regiões brasileiras, não o era na Serra Gaucha: "Quanto à praia, ninguém falava nada, acho que ninguém sabia que tinha ou onde era. Nós, mais de idade, ainda hoje não vamos, pelo menos quem mora na roça”. (JC, 82). Um dos depoimentos relacionados às viagens e suas descobertas, é pelo menos comovente, considerando-se que os entrevistados viviam em cidades distantes da orla marítima: "Quando eu tinha 50 anos, eu acho, a gente foi conhecer o mar. [...] Foi assim. Quando chegamos lá, sentir aquele cheiro daquela água, eu disse: 'Meu Deus, que coisa mais linda...' Eu achava impossível que aqui, tão perto, tivesse o mar e tanta água. Depois disso comecei a ir e agora a gente vai todos os anos, fica quatro, cinco dias, mas a gente vai dar uma volta”. (IBM, 67).

No momento atual, as viagens desses idosos começam a ocorrer com maior freqüência, não só pelas condições de vida, mas por que "Existem muitos meios de transporte e a hospedagem é farta e tem para todos os gostos. As agencias de turismo facilitam muito a vida dos viajantes”. (AMPR, 72). Isso fica evidenciado no depoimento de IBM (67): “[...] agora a gente vai mais longe, né. Eu fui conhecer Brasília. Muitos na minha idade não conhecem. Fui para Goiás, fui pra Caldas Novas, fui pra Piratuba, aqui pra Santa Catarina. E pretendo visitar o Rio de Janeiro e muitos outros lugares. Se Deus me permitir um pouco de saúde e sobrar um pouco de dinheiro, né. (risadas) [...] eu conheço quase toda cidade de Porto Alegre, mas não pra ficar e ver, mas a gente conhece de quando a gente passa por lá”. No novo vivenciar das viagens talvez possa ser sintetizado também nas palavras de IBM: "E dou mais um conselho, que vão conhecer, conhecer porque a gente não vai ficar aqui pra sempre”. Outro destaque é que a palavra turismo começa a aparecer, para significar a viagem: "Acho o turismo de extrema importância para adquirir cultura e conhecer novas formas de vida, além ser uma ótima forma para reunir e descontrair a família. Não precisam ser viagens longas, mas o 
simples fato de sair da rotina faz a gente voltar com outro ânimo para casa. É muito bom!" $(M F, 63)$. Esse tempo de turismo também é visto como um tempo melhor: "Hoje em dia as coisas mudaram muito, temos ônibus passando em frente de casa toda hora. Faço parte de um grupo de melhor idade e viajamos par diversos lugares, inclusive ano retrasado fizemos uma viagem para Argentina." (MMD)

A viagem aparece constantemente associada ao lazer, mas como resposta à pergunta sobre como seria o lazer na sua juventude, outras atividades foram lembradas. O mais citado pelos idosos entrevistados foi a frequência a bailes, logo seguida de expressões como "havia muito respeito" e "não é como hoje em dia", referindo-se aos divertimentos noturnos e em referência ao que seria a total liberdade da juventude contemporânea. Os bailes, de acordo com os relatos, aconteciam aos domingos à tarde, no salão da capela do lugar ou na residência de alguém "onde vinha o gaiteiro. A gente se divertia muito". (IBM, 67). O pai ou um irmão mais velho acompanhava as moças, mas "tinha que chegar em casa antes do escurecer". (FZ, 76). Outra entrevistada disse o seguinte: "Quando íamos a algum baile, sempre os nossos pais iam junto, e ficávamos bem pouco tempo. Quando um rapaz me chamava para dançar, sempre antes ele pedia a permissão ao pai. Se o pai me deixava, eu ia dançar”. (RMZ, 72). As respostas denotam o respeito à hierarquia familiar e aos mais velhos.

Os bailes são muito citados, inclusive como razão para os deslocamentos. A festa de colônia foi citada por uma das entrevistadas como atividade de lazer; vale lembrar que estas festas ocorriam uma vez ao ano, geralmente em comemoração ao santo padroeiro da comunidade. IK (65) afirmou que na sua adolescência, “a opção eram os bailes e reuniões dançantes nas comunidades, que não aconteciam sempre, e quando iam ajudavam os músicos a carregar os instrumentos, e alguns iam de cavalo. Iam todos juntos, amigos, vizinhos, primos. Apenas os homens pagavam entrada e as moças não podiam dizer que não queriam dançar, era considerada falta de respeito". Nos bailes bebia-se café e vinho e comia-se "bolo, rapadura, cuca, salame, queijo, copa [...].” (VB, 61)

$\mathrm{O}$ entrevistado ACS (66) acrescenta que "também se fazia piqueniques com os amigos $e$ encontros de família" e, no "domingo a tarde tinha matinê e quando o pai deixava, eu vinha com minhas irmãs e meu irmão, mas antes da noite tinha que estar em casa" (AMC, 89). O domingo, ainda, "era mais divertido, pois vinham os amigos e brincávamos de se esconder, de se pegar, de ovo choco". (JC, 82). As brincadeiras de final de semana ainda poderiam 
incluir "jogos simples, como cabra-cega, corrida, jogos de carta como bisca, pife, quatrilho... Com o passar do tempo, até umas paqueradas discretas com alguns rapazes, mas nada comprometedor, já que as coisas eram muito diferentes naquele tempo.” (MMD). Já aos sábados era dia de "ir ao filó na casa dos vizinhos, jogar carta, tomar vinho. Íamos com 'il ciareto ${ }^{\prime 10}$ porque não tinha luz. Era uma grande alegria, ninguém se importava em caminhar, estávamos acostumados”. (AMC, 89)

Apresenta-se na Figura 2, que segue as formas de lazer mais citadas pelos idosos entrevistados, para que se possa ter uma apreciação crítica dos divertimentos no passado dos participantes do estudo. Destacam-se, nas falas, a participação em bailes, seguida da atividade religiosa, em especial a missa. O filó aparece em terceiro lugar, mesmo que se tratasse de um evento mais roteiro, na sua característica de reunir a vizinhança.

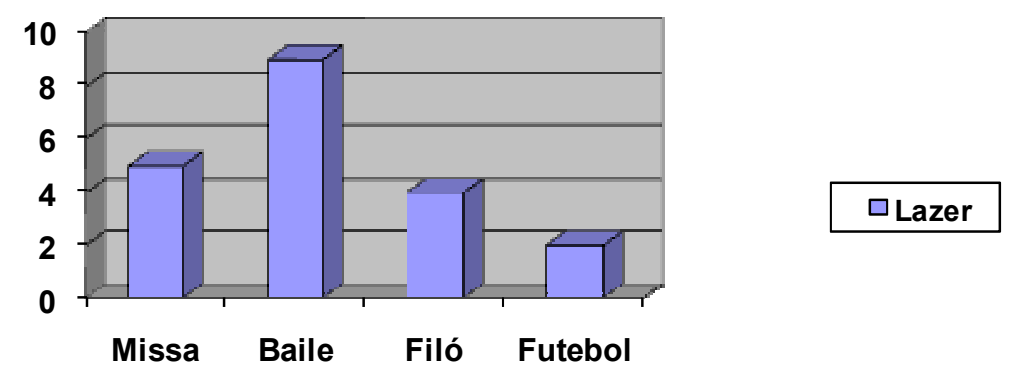

Figura 2 - Atividades de lazer citadas pelos entrevistados

A presença do futebol entre os divertimentos mais citados não deixa de apresentar certa curiosidade. O deslocamento para assistir e participar de jogos foi destacado mesmo pelos mais idosos e, inclusive, pelas mulheres. Segundo as entrevistadas, o grupo costumava viajar sobre um caminhão até a comunidade onde os jogos aconteciam. Os homens eram os atletas, as mulheres as torcedoras: "E aí, a viagem que a gente fazia era pra fazer torcida de futebol, que já tinha naquela época. Que o nono, o vô, era goleiro. Naquela época os meus irmãos jogavam. E a gente ia quando eles iam pra fora, por exemplo, pra Garibaldi (...). A gente ia junto, de caminhão. E a gente gritava, fazia torcida, brigava... (risadas). (IBM, 67). A

\footnotetext{
${ }^{10}$ Tipo de lampião.
} 
entrevistada AMC (89) também cita o esporte como motivador aos deslocamentos: “O mais longo que íamos (...) (era) acompanhar os homens que vinham jogar futebol". O futebol também é apresentado como o lazer dos domingos, dia distribuído entre a missa, pela manhã, e as peladas, à tarde: "nos domingos havia a missa, tinha os jogos de futebol também nas proximidades, no domingo a tarde. Era divertido.” (MIPL, 82). Mas a semana, não era dedicada apenas ao trabalho, pois poderia haver o "serão", que era uma reunião na casa de vizinhos, quando "jogávamos baralho, conversávamos, comíamos pipoca, pinhão e tomávamos chimarrão" (VB, 61).

Era um tempo melhor? Para IBM (67), "a gente passou assim, como dava. A gente dava um jeito de se divertir.” Para MIPL (82): “Apesar das dificuldades éramos felizes e mais do que hoje”; esta fala é uma exceção em um grupo que tende a apresentar o hoje como melhor do que os duros tempos de trabalho de quando eram jovens.

O trabalho de campo concretizado com as entrevistas feitas com os idosos participantes da pesquisa permitiu reflexões significativas sobre questões relativas às viagens, deslocamentos e os lazeres na época de juventude e que permitiu a análise e discussão das informações que apresentamos em continuação.

\section{Refletindo Sobre as Informações}

As informações recolhidas por meio das entrevistas revelam as dificuldades nos deslocamentos e nas viagens em diferentes décadas do século XX, em especial de 1940 em diante, no interior do Rio Grande do Sul. As dificuldades não ficavam resumidas aos deslocamentos e viagens em si, por estradas precárias ou mesmo inexistentes, mas incluem a falta de estruturas complementares ao viajar. Os viajantes eram obrigados a providenciar pessoalmente a alimentação a ser consumida durante o percurso, na forma de alimentos não perecíveis como pão, queijo e salame, além do vinho, preparados no ponto de partida e que deveriam durar até o final da viagem. Mas, mesmo assim, as viagens não deixaram de ocorrer e foram cuidadosamente guardadas na lembrança.

Os mais velhos, ou seja, aqueles com mais de 80 anos, e reportando provavelmente às décadas de 1930/1940, citaram percursos nas matas percorridos a pé ou a cavalo. As primeiras estradas surgem nos anos 1940, mas só os mais ricos tinham o privilégio de ter uma charrete. Na sua 
falta, o carro de boi cumpria a função de transportar pessoas e mercadorias. Em tempos mais recentes e para aqueles com melhores condições financeiras, o caminhão utilizado para o trabalho, em situações especiais, servirá também para os deslocamentos sociais do grupo.

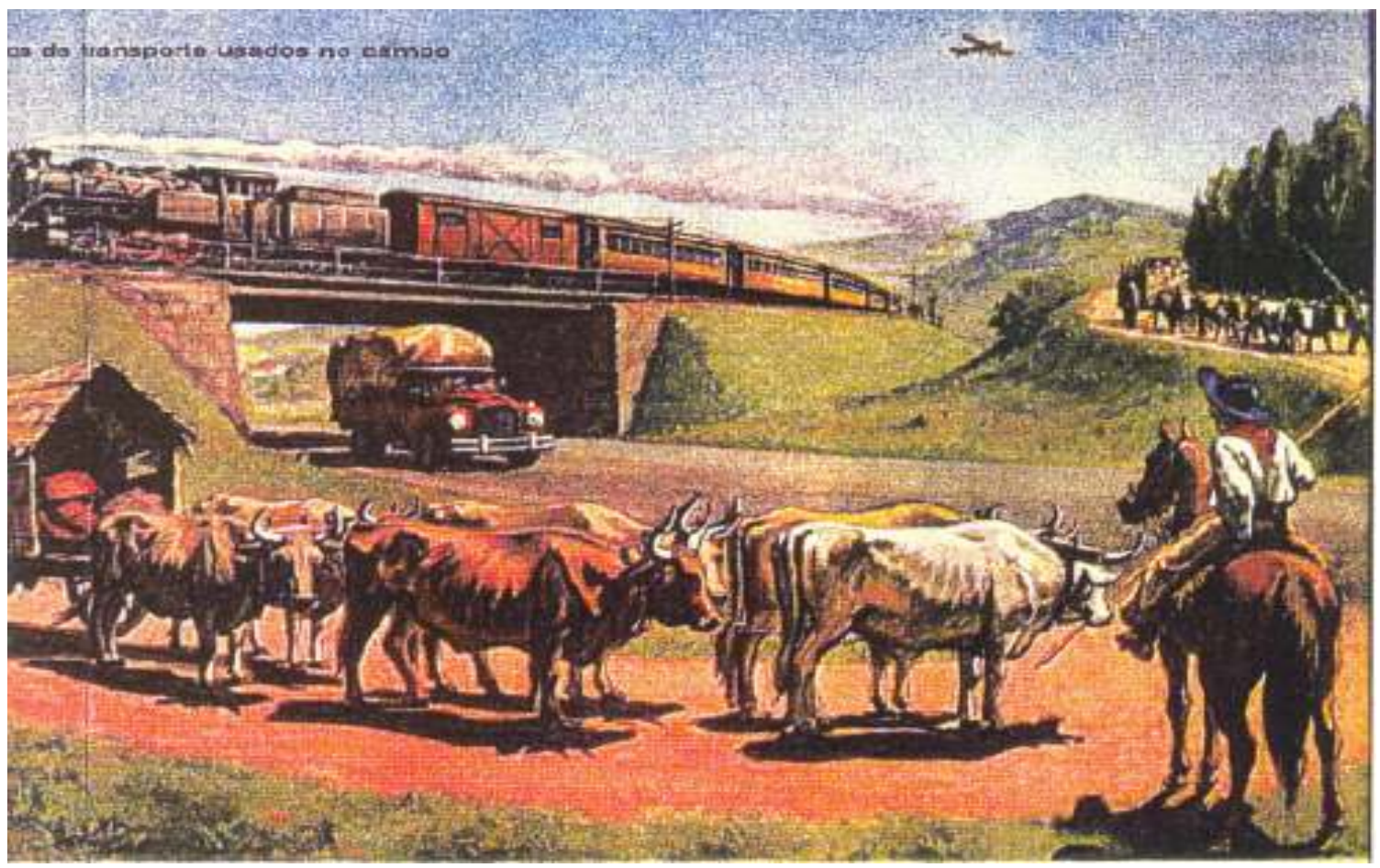

\section{Figura 3 - Meios de transportes usados no campo}

Fonte: ZEUNER, E. Meios de transportes usados no campo. Serie Aspectos da Vida no Brasil. Guache sobre cartão, $20 \mathrm{~cm} \mathrm{X} 14.5 \mathrm{~cm} .1950 \mathrm{c}$

Esta situação corresponde ao que é apresentado em outro documento, produzido nos anos 1950, que fica muito próximo do relatado nas entrevistas. O artista Ernest Zeuner registra uma imagem em que há carros de boi percorrendo estradas de chão batido, mas também os primeiros caminhões e a presença do trem. No céu, a direita, aparece discretamente um pequeno avião, embora o mesmo não tenha sido citado em nenhuma entrevista. Zeuner intitulava seu trabalho como "Meios de transportes usados no campo."

O caminhão foi citado nas entrevistas como meio de transporte também utilizado em alguns deslocamentos de lazer, fundamentalmente quando havia alguma festa na região ou para participação em jogos de futebol. As pessoas viajavam na carroceria do caminhão sem nenhum tipo de conforto ou segurança, mas, mesmo assim, na lembrança dos idosos essa 
viagem era divertida: "sempre que se viajava era uma festa" (IBM, 67), ou, como colocado por NP (76), "era possivel sempre achar uma diversão sadia durante as viagens."

Outro aspecto cultural que merece destaque, diz respeito à religiosidade. Por se tratar de comunidades de ítalo descendentes, a religiosidade deveria ser praticada e expressa com presença em missas, mesmo que houvesse dificuldade de deslocamento. Por outro lado, esse deslocamento religioso também era considerado, de certa forma, como lazer. De acordo com os relatos colhidos, o lazer ocorria em torno da capela após a missa e a realização dos terços. Nessa oportunidade, os homens costumavam participavam de jogos de cartas e futebol.

O lazer feminino estava associado aos bailes, ao assistir jogos de futebol, para torcer pelos homens da família e aos filós. Os filós ocorriam com frequência, geralmente na casa de alguém da vizinhança, onde as mulheres faziam trabalhos manuais e os homens jogavam cartas. Percebe-se pelos depoimentos a importância dada a integração durante as atividades de lazer, pois mesmo que as distâncias fossem difíceis de serem vencidas, as pessoas buscavam formas de participar.

Assim como citado por Bosi, a expressão “hoje já não existe mais", foi uma constante nas respostas dos idosos entrevistados. A outra expressão muito presente nas entrevistas foi a "hoje é tudo mais fácil" ao se referirem às questões do deslocamento. Os entrevistados lembraram que, na sua juventude, ninguém possuía automóvel, quando faziam referências aos parentes e vizinhanças.

Além de fornecer informações de como eram os deslocamentos a cerca de 50 ou 60 anos atrás, as entrevistas possibilitaram aos entrevistadores conhecer uma realidade vivida num passado agora distante e que tende a ser esquecido devido a pouca atenção dada às pessoas idosas. As entrevistas além das informações precisas e pontuais dadas pelos entrevistados idosos, também os fez sentir prazer por fornecer as informações. O estudo também colocou de manifesto a riqueza da memória oral estratégia de investigação, fundamentalmente, na área do turismo, uma vez que permite o contato direto com o sujeito objeto de estudo e conhecer a história de determinados lugares. Pesquisa realizada com pessoas idosas por Lobo (2000) já havia revelado que um dos prazeres das pessoas de idade avançada é ter alguém para escutálas a contar um pouco da sua vida. 
Quanto ao imaginário da viagem, o item mais importante talvez seja que os deslocamentos estavam presentes, em que pese as dificuldades, para situações de trabalho mas, principalmente, para situações de lazer. Outro fator importante é que a viagem não era medida pela distância percorrida ou pelo tempo despendido, estando sua construção de sentido associada ao sair das rotinas do pequeno mundo doméstico.

O que também se percebe é que a motivação evolui, sendo associada nos tempos mais remotos a obrigações religiosas, como a missa, e a presença em rituais sociais de casamentos, funerais e batizados; posteriormente, a motivação estará associada ao casamento, no desfrute da lua-de-mel.

Por fim, os depoimentos registram o prazer da viagem no momento presente de vida do idoso, por abrir novas perspectivas de mundo: “Ah, juventude sempre é bom. A gente vai passear e tem, como é que se diz?, sonhos, né. Sonhos...E depois a gente sonha que é uma coisa e na verdade é outra, mas também não foi ruim, e nem agora está sendo. (...) Teria tanta coisa pra contar... (...) Tenho 67 anos, mas pelo menos eu conheci. Como eu to dizendo, tem mulheres da minha idade que não conhecem o que eu conheci, o que eu vi, e eu pretendo ir, de vez em quando, dar mais uma passeada, me distrair. ” (IBM, 67) E, como já colocado, IBM reforça: "E dou mais um conselho: que vão conhecer! Conhecer, porque a gente não vai ficar aqui pra sempre."

\section{Referências}

BARBOSA, Ycarim Melgaço. 2002. História das Viagens e do Turismo. São Paulo: Aleph.

BOSI, Ecléa. 1994. Memória e sociedade: lembranças dos velhos. $3^{\text {a }}$ Ed. São Paulo: Companhia das Letras.

BOYER, Marc. 2003. História do Turismo de Massa. Bauru: EDUSC.

CARDOSO, Sílvia Helena. 1997. Memória: o que é e como melhorá-la. Revista Mente e Cérebro. N.01. Disponível em: <http://www.cerebromente.org.br/n01/memo/memoria.htm>. Acesso em: 27/03/2009

IZQUIERDO, Ivan. 1999. Entre os segredos e as revelações do cérebro. Entrevista dada a jornalista Miriam Gusmão. Jornal da Universidade - UFRGS. Porto Alegre, Ano II, nº 21, Julho.

IZQUIERDO, Ivan. 1999. Memória. Porto Alegre: Artmed.

KURY, Mário da Gama. 1990. Dicionário de Mitologia Grega e Romana. Rio de Janeiro: Jorge Zahar

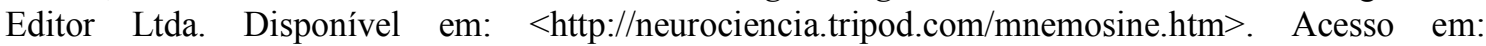
20/05/2009. 
LEED, Eric J. 1991. The mind of the traveler: from Gilgamesh to global tourism. Estados Unidos/sl: Basic Books.

LOBO, A. S. 2000. Terapia corporal no meio aquático com pessoas na terceira idade. Dissertação de Mestrado. Programa de Mestrado Interinstitucional entre ESEF/UFRGS. Curso de Pós-Graduação em Ciências do Movimento Humano e UCS.

KESSEL, Zilda. s/d. A memória e as épocas. Disponível em: <http://www.educarede.org.br/ educa/index.cfm?pg=oassuntoe.interna\&id_tema=18\&id_subtema=1> Acesso em: 27/03/2009.

MENEZES, José Newton Coelho. 2006. História e turismo cultural. Belo Horizonte: Autêntica.

REJOWSKI, Mirian. 2002. Turismo no percurso do tempo. São Paulo: Aleph.

TONUS, João Wianey (org.). 2007. Victur: valorização do turismo integrado à identificação dos territórios. Caxias do Sul: Belas-Letras.

Recebido em: 10/08/2009

Aprovado em: 02/02/2010 